\title{
A TWO-GENERATION REPRODUCTIVE TOXICITY STUDY OF DICYCLOHEXYL PHTHALATE IN RATS
}

\author{
Nobuhito HOSHINO ${ }^{1}$, Mayumi IWAI ${ }^{1}$ and Yoshimasa OKAZAKI ${ }^{2}$ \\ Toxicology Division I ${ }^{1}$, and Pathology Division ${ }^{2}$, Kashima Laboratory, Mitsubishi Chemical Safety Institute Ltd, \\ 14 Sunayama, Kamisu-shi, Ibaraki 314-0255, Japan
}

(Accepted October 18, 2005)

\begin{abstract}
The reproductive toxicity of dicyclohexyl phthalate (DCHP) was evaluated in a two generation test in which male and female Sprague-Dawley (SD) rats of parental (F0) and F1 generation were exposed to DCHP in the diet at concentrations of 0 (control), 240, 1200 or $6000 \mathrm{ppm}$. With regard to the effects on the F0 and F1 parental animals, changes included inhibition of body weight gain and food consumption, diffuse hypertrophy of hepatocytes, and hypertrophy of thyroidal follicular epithelial cells at the doses of $1200 \mathrm{ppm}$ and $6000 \mathrm{ppm}$. The following changes were observed in the $6000 \mathrm{ppm}$ group: increase weights of the liver and thyroid, increased hyaline droplets in the renal proximal tubular epithelium (F0 and F1 males), reduction of prostatic weight (F1 males), and diffuse and/or focal atrophy of testicular seminiferous tubules ( $\mathrm{F} 1$ males). In addition, slight prolongation of the estrous cycle was noted in the F0 females of the $6000 \mathrm{ppm}$ group, along with reduced spermatid head counts in the testes (homogenationresistant spermatids) in F1 male receiving doses of $1200 \mathrm{ppm}$ or $6000 \mathrm{ppm}$. It is thought that the prolonged estrous cycle was secondary to the suppression of body weight gain. There were no test substance related changes in clinical signs and reproductive capability (mating, fertility, gestation and birth index), or in data for the delivery and lactational periods, or serum hormone levels. With regard to effects on the offspring, inhibition of body weight gain was found in the F1 and F2 6000 ppm, and decrease of anogenital distance (AGD) and appearance of areola mammae were observed in the F1 male 6000 ppm and F2 male receiving doses of $1200 \mathrm{ppm}$ or $6000 \mathrm{ppm}$. No effects of DCHP treatment on the offspring were observed on results of clinical signs, the number of the pups delivered, sex ratio, viability, physical development, reflex and response tests, external abnormalities, organ weights, or necropsy findings. From the present study of DCHP administered to rats over two-generations, the no observed effect level (NOEL) for effects on the parental animals including the endocrine system, is considered to be $240 \mathrm{ppm}$. With regard to the reproductive toxicological effects on the parental animals, the NOEL is $240 \mathrm{ppm}$ for males and $1200 \mathrm{ppm}$ for females. For offspring, the NOEL values are concluded to be $240 \mathrm{ppm}$ for males and $1200 \mathrm{ppm}$ for females.
\end{abstract}

KEY WORDS: Dicyclohexyl phthalate, Two-generation, Reproductive toxicity, Rats

\section{INTRODUCTION}

Dicyclohexyl phthalate (DCHP) is a common plasticizer ingredient for production of nitrocellulose, ethyl cellulose, vinyl acetate, polyvinyl chloride, and resins (HSDB, 2001). Since DCHP neither binds to human estrogen receptors nor induces transcriptional activation through human estrogen receptors, it is reported to have limited potential for endocrine disruption via sex hormone receptors (METI, 2002). How- ever, related phthalate compounds were found to reduce the anogenital distance (AGD) and cause hypospadias and nipple retention in male offspring (Fisher, 2004). To ascertain whether DCHP might similarly exert reproductive and developmental toxicity the present two-generations study was performed on the reproductive capability of parental animals as well as the growth and development of offspring. Moreover, the presence or absence of endocrine disrupting action was assessed.

Correspondence: Nobuhito HOSHINO (E-mail: n-hoshino@ankaken.co.jp) 
As part of the "Developmental Project of Evaluation and Testing Methods for Endocrine Disrupting Effects of Chemical Substances", a research project by the New Energy and Industrial Technology Developmental Organization (NEDO), feed containing DCHP feed was administered to rats over two successive generations and the effects on the reproductive capability in the parental animals and growth and development of the offspring were investigated.

This study was carried out in accordance with OECD guideline for the testing of chemicals No.416 (OECD, 1983).

\section{MATERIALS AND METHODS}

\section{Chemical}

Dicyclohexyl phthalate (DCHP, CAS No. 84-617) for study was provided by MERCK-Schuchardt OHG., (Hohenbrunn, Germany) and mixed into the diet (NIH-07M, CLEA Japan, Inc.). The DCHP was 99.9\% pure (Lot No.: S26063).

\section{Animals and housing conditions}

International Genetic Standard rats (Crj:CD(SD)IGS, Charles River Japan, Inc. [Astugi breeding center]) were employed. Twenty-four male and female rats were used in each group. Administration was started at five weeks of age in the F0 parental animals. After quarantine and acclimatization for 5 days, healthy rats were subjected to the study. Animals were reared on basal diet (NIH-07M, CLEA Japan, Inc.) and tap water irradiated by ultraviolet-ray after filtration through a $5 \mu \mathrm{m}$ filter was given ad libitum using water bottles. They were housed in an animal room controlled with the temperature at $19.0^{\circ}-25.0^{\circ} \mathrm{C}$, the relative humidity at $35.0 \%-75.0 \%$, the number of ventilation at about 12 times/hour, and the light and dark cycle at 12 hours (turn on at 7 o'clock and off at 19 o'clock). They were placed in polycarbonate cages with bedding for laboratory animals. Administration to the F0 parental animals was started at five weeks old.

\section{Dosing}

A preliminary dose range finding study was conducted with DCHP administered to rats at doses of 0 , $600,2000,6000$ or $20000 \mathrm{ppm}$ during the period from three weeks or more pre-mating through the mating period, until necropsy for the males, and through gestation and lactation periods until postnatal day 21 (PDN 21) for the females. With regard to effects on the parental animals, in the 20000 ppm group, inhibition of body weight gain and increase in hepatic weights were observed in males and females, along with increase in adrenal weights and decrease in the weights of the thymus, spleen and ovary in the females. In the 6000 and 2000 ppm groups, increase or a tendency for increases in hepatic weights were found in both females and males, and a similar tendency was also shown in the females of the 600 ppm group. No effects on reproductive functions, delivery or lactation were found in any dose group. Regarding effects on the offspring, inhibition of body weight gain was observed in both males and females of the $20000 \mathrm{ppm}$ group, and a similar trend was found in the $6000 \mathrm{ppm}$ group. Based on these findings, the highest dose for the main study set at $6000 \mathrm{ppm}$, with middle and lowest doses of 1200 and 240 ppm, respectively, by dividing with the common ratio of 5 .

\section{Administration period}

The rats received DCHP in the diet. Administration to F0 parental animals was started from the age of five weeks for both males and females; administration to F0 males was continued until necropsy through 10 weeks or more of the pre-mating and mating periods, while administration to F0 females lasted until necropsy through 10 weeks or more of the pre-mating, mating, gestation, and lactation periods until weaning of the F1 offspring (PND 21). Administration to F1 parental animals was started from the time of weaning (three weeks old) and was continued for F1 males until necropsy through 10 weeks or more of the pre-mating and mating periods, and similarly for F1 females through 10 weeks or more of the pre-mating, mating, gestation, and lactation periods until weaning of the F2 offspring (PND 21). Administration to the non-delivering F0/F1 animals continued until necropsy, which was conducted at least 26 days after confirmation of copulation.

\section{Mating procedures}

At the age of 15 weeks after the 10-week administration period starting from five weeks of age for the F0 animals, and at the age of 14-15 weeks after the 10 week or longer administration period from three weeks of age in the F1 animals, females were moved to the cages of male partners in the evening, and the males and females cohabited at a sex ratio of 1:1 through the mating period. The existence of a vaginal plug or sperm in the vaginal smear was assessed every morning from the following day. When either was detected, it was judged that copulation had occurred and the day 
Reproductive toxicity study of dicyclohexyl phthalate.

was defined as gestation day (GD) 0 . The mating period was limited to two weeks. Pregnancy was confirmed by investigating the existence/absence of delivery and/or implantation sites at the time of necropsy.

For the F1 parental animals, one male and female were selected randomly from each litter on PND 21. Necropsy of the other offspring was performed on the same day.

\section{Experimental design \\ 1. Parental data \\ 1) Observation and measurements for parental ani- mals}

All adult rats were observed daily for clinical signs of toxicity, and body weights and food consumption were recorded weekly. The body weights and food consumption of copulation-confirmed females were measured on GDs 0 (the day when copulation was confirmed), 7, 14, and 20, on lactation days (LDs) 0, 4, 7, 14 , and at necropsy after weaning (day 21 of lactation).

\section{2) Estrous cycle}

Vaginal smears were collected from the females everyday in the morning to examine the estrous cycle during the two weeks before mating, starting from 13 weeks of age for $\mathrm{F} 0$ parents and from 11 weeks of age for F1 parents, and the mean days of the estrous cycle were calculated. Estrous cycles other than 4 to 6 days were regarded as abnormal.

\section{3) Sperm examination}

Sperm motility of ten animals of the parental animals in each F0 or F1 group was assessed with a sperm auto-analyzer (HTM-IVOS Ver.10.8). Ten animals of the control and 6000 ppm groups were also randomly selected for counts of the numbers of homogenizationresistant spermatids in the testes (spermatid head counts) and numbers of sperm in the cauda epididymal determined with the sperm auto-analyzer (HTM-IVOS Ver.10.8). A statistically significant difference in the numbers of homogenization-resistant spermatids in the testes was evident between the 6000 ppm group and the control in the F1 parents, so that sperm examination was also added for the 240 and 1200 ppm groups. Furthermore, ten animals each in the control and 6000 ppm groups, smear specimens were prepared and examined for morphologically abnormal sperm to calculate their appearance rate.

\section{4) Serum hormone levels}

Six males of the F0 and F1 parents for each treat- ment group were randomly selected for hormone measurement at necropsy. Females were examined for estrous cycling everyday in the morning after completion of the lactation period, and six in each treatment group in the proestrous stage were randomly selected, then left for about one hour after being taken out from the animal room and then sacrificed to collect blood samples by decapitation without anesthesia at an almost constant time after 1:00 p.m. Using sera separated from the blood samples, testosterone, FSH and $\mathrm{LH}$ in the males and estradiol, FSH and LH in the females were measured by the RIA method. The hormone measurement was carried out at Panapharm Laboratories Co., Ltd.

\section{5) Organ weights}

The following organs were weighed in all the F0 and F1 parental animals: the brain, pituitary gland, thyroid including parathyroid, liver, kidneys, adrenal glands, spleen, testes, epididymes (whole and caudal parts), prostate (ventral lobe), seminal vesicles (including the coagulating glands), ovaries, and uterus (including the cervical region).

\section{6) Pathological and histopathological examinations}

All the parental animals sacrificed or found dead were necropsied.

Histological examination was conducted for the following organs from all the male and female F0 and F1 parents of the control and the 6000 ppm groups: the brain, pituitary gland, thyroid including parathyroid, liver, kidneys, adrenal glands, spleen, testes, epididymes, seminal vesicles (including coagulating glands), prostate (ventral lobe), ovaries, uterus (including the cervical region), vagina, and mammary glands. Furthermore, histopathological examination was performed for the groups receiving the doses of 240 or $1200 \mathrm{ppm}$ were conducted as follows: for the liver and thyroid in the male and female F0 and F1 parent animals, for the kidneys in male F0 and F1 parents, for testes in male $\mathrm{F} 1$ parents, for adrenals in male and female F1 parents and for macroscopic abnormal sites observed were examined. In addition, any animals that died during the course of the study were examined to investigate the cause of death.

\section{Litter data (offspring parameter) 1) Observation and measurements for offspring}

The pups were observed for clinical signs from the outside of the cage everyday through the lactation period. When body weights were measured, each was 
individually and closely observed in the investigator's hands. The number of the pups per litter was adjusted randomly to eight (four each of the males and females when possible) on PND 4 . When the number of the pups per litter was less than eight, they were housed as is. The pups not selected at the adjustment were sacrificed by exposure to carbon dioxide gas and their whole bodies were stored in $10 \%$ neutral phosphatebuffered formalin solution.

Body weights were measured on PNDs 0, 4, 7, 14, and 21. The anogenital distance (AGD: the distance between the anus and the genital node) was determined on PND 4 following adjustment of the number of pups. The relative AGD value divided by cubic root of the body weight on the measurement day was also calculated. The F1 and F2 pups were observed for the appearance of areolae (or nipples) on PND 14* and on PND 12*, respectively, and appearances rates (incidences) were calculated.

* Regarding the reason for the difference in observation day between the F1 and F2 pups: observation of the appearance of nipples was not scheduled in the original study protocol. However, when F1 pups were observed for clinical signs on PND 14, areolas were observed in the males of the 6000 ppm group. Therefore, observation of the existence of nipples was performed on PND 14 in the F1 pups, and on PND 12 in the F2 pups, when definitive evaluation could be accomplished.

\section{2) Physical development and sexual maturation}

The incidence of pinna unfolding was calculated by observation of all offspring from PNDs 2 to 4 . Offspring were also observed and examined for the day on which the completion of the following parameters occurred before weaning: upper incisor eruption from PND 6 and eye opening from PND 10.

Regarding sexual maturation, preputial separation in the males and vaginal opening in the females employed as parameter, and the F1 animals were individually observed during the period from PND 35 or PND 27 until completion of male or female sexual maturation, respectively, and the body weights were measured on the day of completion.

\section{3) Reflex response tests}

All live pups were examined on PND 19 for their pain response, negative geotaxis, air righting reflex, and the pinna reflex, then the positive rates were calculated.

\section{4) Organ weights (weaning)}

The brain, thymus and spleen of single F1 and F2 male and female offspring selected from each litter were weighed on PND 21.

\section{5) Pathological examination}

Excluding the pups that died before selection on PND 4 or the pups not selected on PND 4 (when their numbers were adjusted), all the remaining pups were necropsied when they were sacrificed or found dead.

\section{Statistical analyses}

Data concerning effects on the offspring until their weaning were based on values calculated per litter as the specimen unit. Using weights of bilateral organs, the sums of the left and right organs were employed for statistical analysis.

Metric data were analyzed for homogeneity of variance by Bartlett's method (Bartlett, 1937). When the variance was homogeneous, one-way ANOVA was carried out. When not homogeneous, on the other hand, a Kruskal-Wallis's test (Kruskal and Wallis, 1952) was performed. When a significant inter-group difference was found, Dunnett's method (Dunnett, 1955) or a Dunnett type multiple-comparison method (Dunnett, 1964) were applied. For some examination items, the Kruskal-Wallis test was applied first, and when a significant inter-group difference was found, Dunnett type multiple-comparison method was conducted. Numerical data were analyzed by the Fisher's exact probability method (Fisher, 1955). The level of statistical significance was basically set at $5 \%$.

For clinical signs, necropsy, and histopathological findings, no statistical analyses were performed.

\section{RESULTS}

\section{Data of parental animals}

1) Clinical signs, body weight and food consumption

No treatment-related changes were observed in clinical signs in the F0 and F1 parental animals of any dose group. No deaths occurred during the study period in either sex of the F0 parents. Of the F1 parents, one female in the $240 \mathrm{ppm}$ group died during delivery on GD 25, and one female in the $6000 \mathrm{ppm}$ group died on PND 26. In the former (the dam in the $240 \mathrm{ppm}$ group), although her delivery started on GD 22 , all the pups died without suckling the milk, and the dam eventually died on GD 25 before all the intrauterine fetuses were completely delivered. In the latter case (in the $6000 \mathrm{ppm}$ group), no specific changes were 
Reproductive toxicity study of dicyclohexyl phthalate.

noted. It was considered that the mortality was caused by systemic worsening of general condition during the puerperal period or by opportunistic infection. As no similar changes were found in scheduled-sacrificed animals, it was judged that the changes were not related to DCHP.

Chemical intake data are shown in Table 1 and body weight data in Fig. 1 and 2. The males and females of F0 and F1 parental animals of the 1200 ppm or higher groups demonstrated inhibition of body weight gain. Food consumption data are shown in Table 2. Treatment with DCHP reduced food consumption in the F1 male parents of the 1200 ppm or higher groups and in the F0 female parents of the $6000 \mathrm{ppm}$ group.

\section{2) Estrous cycle}

Data for estrous cycles in F0 and F1 females are shown in Table 3. In the F0 females receiving 6000 ppm, prolongation estrous cycle was observed but this was not evident in the significant elevation of the estrous cycle F1 females.

\section{3) Reproductive effects}

Reproductive data for $\mathrm{F} 0$ and $\mathrm{F} 1$ animals are shown in Table 4. No significant differences were observed in any dose groups of F0 and F1 parental animals for the following indices; number of days required for completion of copulation, number of estrous stages missed until completion of copulation, mating index, fertility index, gestation length, gestation index, birth index and number of implantations. Furthermore, no effects of the substance were apparent in the results obtained during the delivery and lactation periods. The values for the mating and fertility indices showed slight tendencies for decrease in the $6000 \mathrm{ppm}$ group of the F1 parents, and this was considered associated with the testicular changes (soft and/or small size), recognized in three males at necropsy. In the other males of the same group (the F1 6000 ppm group) copulation and resultant pregnancy were normal.

Data for sperm parameters in F0 and F1 parental males are shown in Table 5. In the F0 male groups treated with the doses up to $6000 \mathrm{ppm}$, no treatmentrelated effects were observed for the sperm motility

Table 1. Daliy chemical intake.

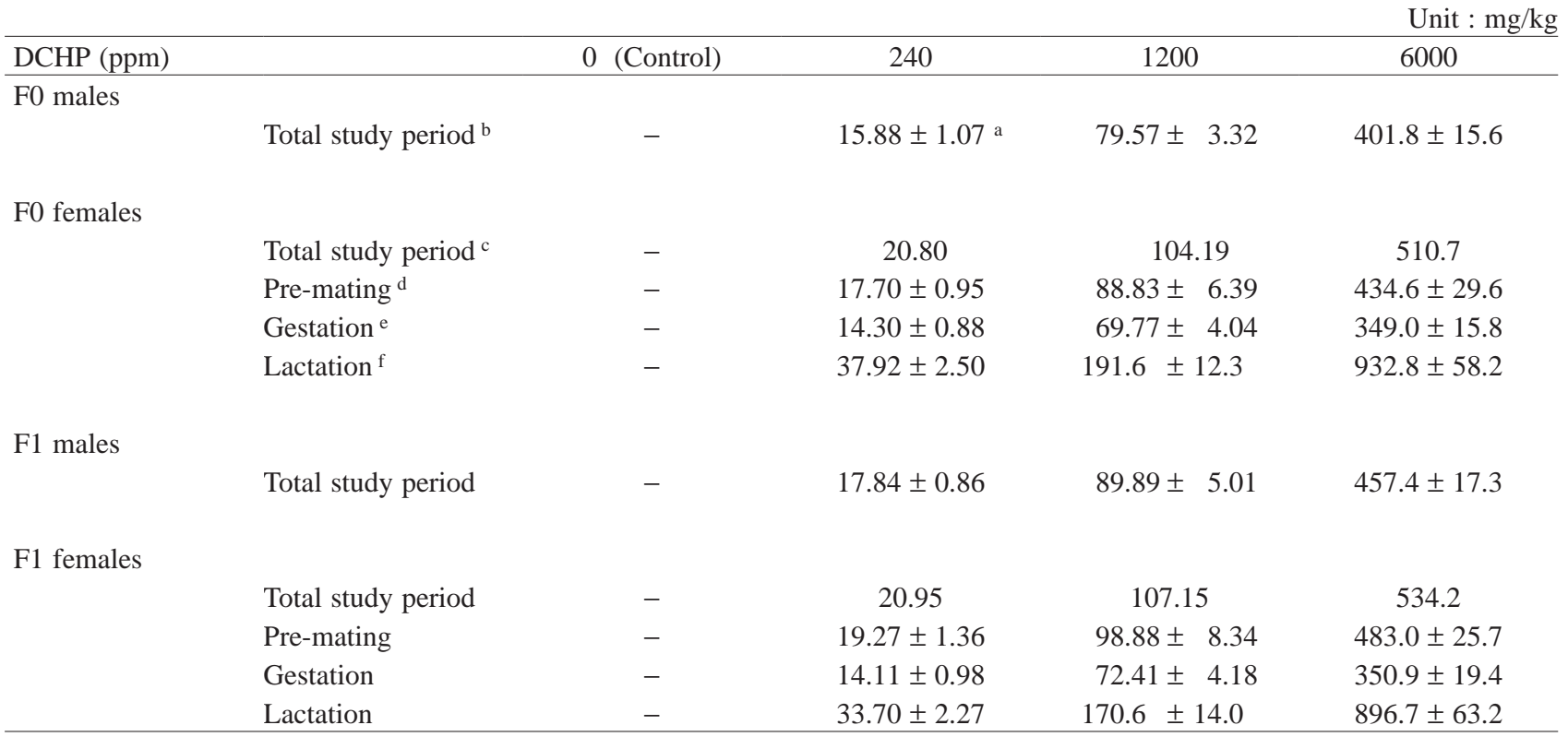

\footnotetext{
a: Mean \pm SD.

b: During the period of 10 weeks.

c: The mean daily intake for the study (pre-mating + gestation + lactation periods).

d: Pre-mating period (10 weeks).

e: Gestation length (Days 21-23).

f: Lactation period (Days 0-21).
} 
rate, number of homogenization-resistant spermatids in the testis, number of sperm in the caudal epididymis, and incidence of morphologically abnormal sperm. In the F1 male parents of the 1200 and 6000 ppm groups, significantly reduced values were observed for the numbers of homogenization-resistant spermatids in the testis. In the F1 male parents of the 6000 ppm group, soft and small sized testes were observed in one ani-
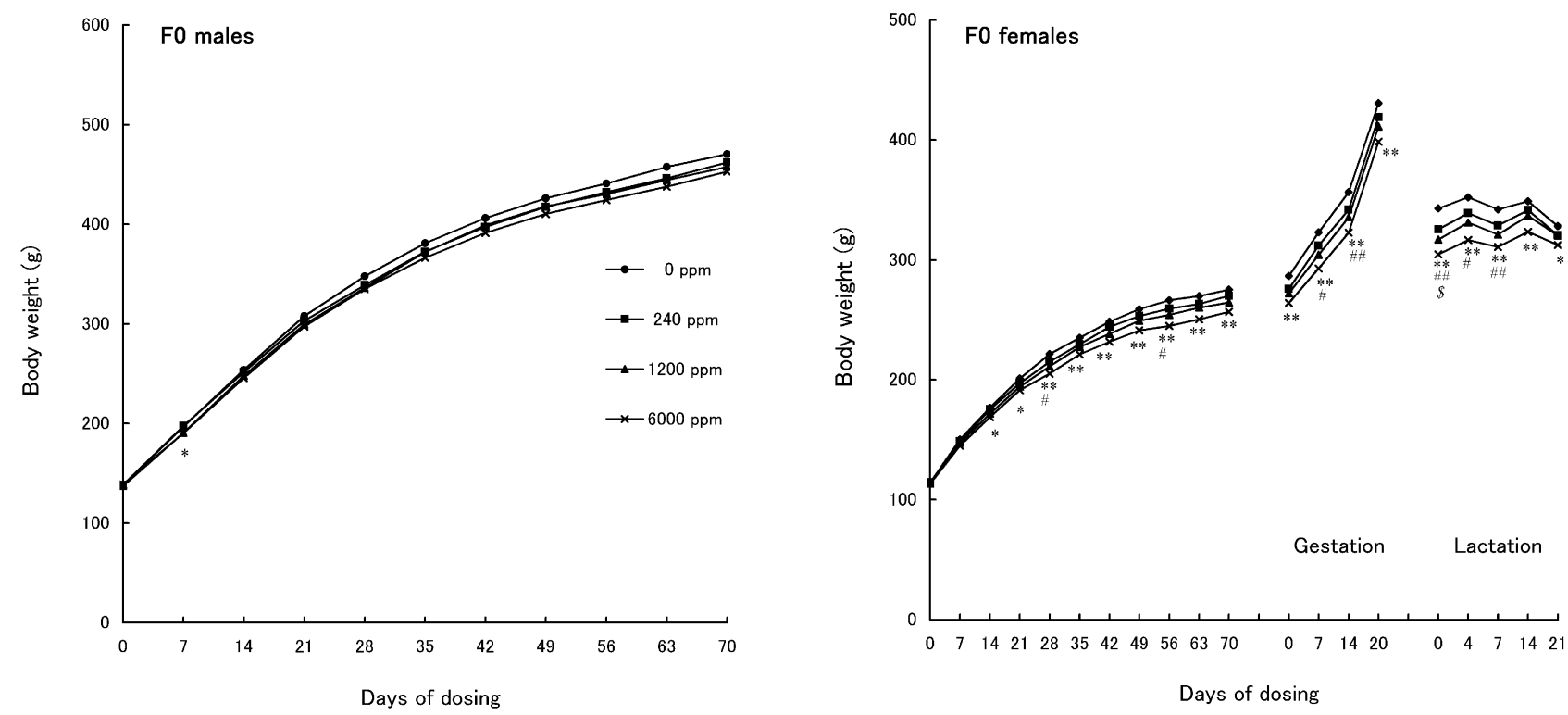

Fig. 1. Parental mean body weights (g) of F0 male and females.

*: Significantly different from the control (6000 ppm group), *, $\mathrm{p}<0.05 ; * *, \mathrm{p}<0.01$.

\#: Significantly different from the control (1200 ppm group), ", $\mathrm{p}<0.05$; \#\#, $\mathrm{p}<0.01$.

$\$$ : Significantly different from the control (240 ppm group), ${ }^{\$}, \mathrm{p}<0.05$.
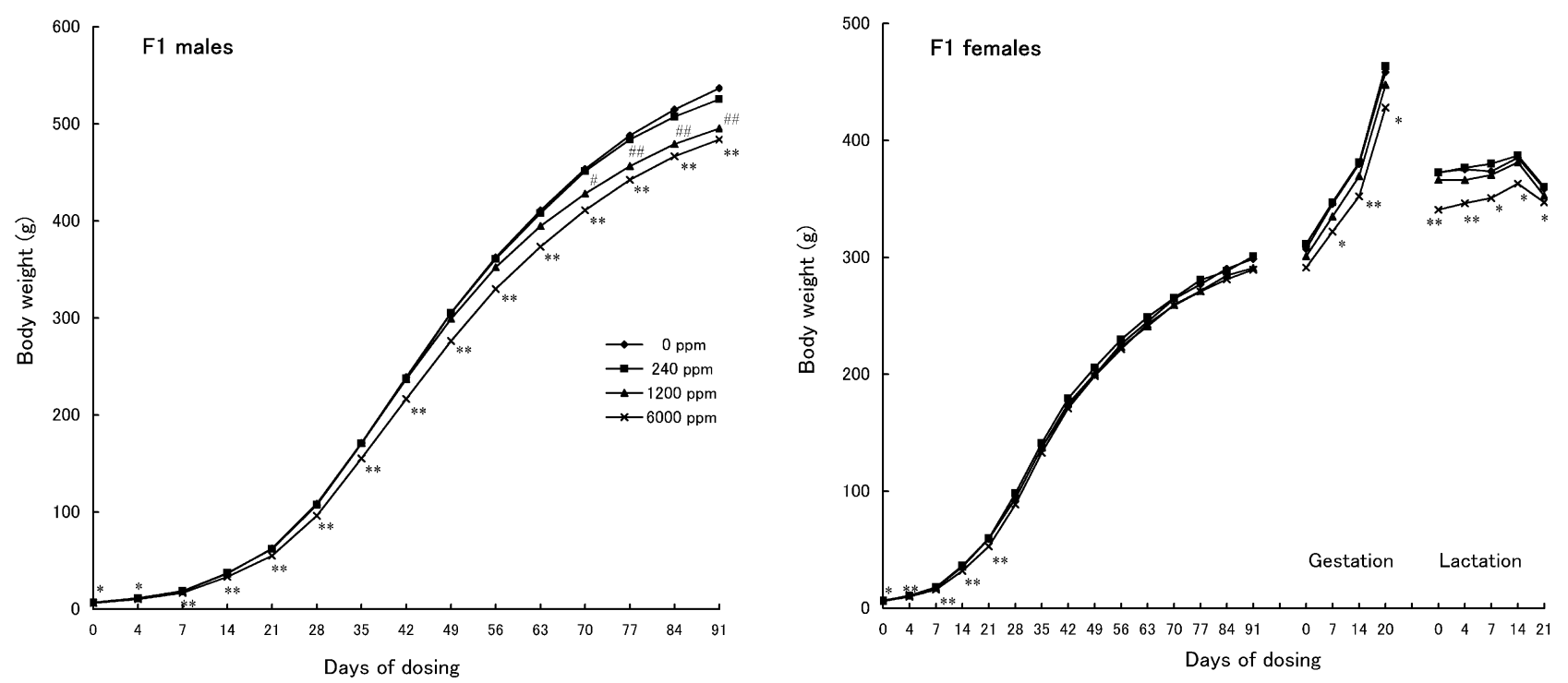

Fig. 2. Parental mean body weights (g) of F1 male and females.

*: Significantly different from the control (6000 ppm group), *, $\mathrm{p}<0.05 ; * *, \mathrm{p}<0.01$.

\#: Significantly different from the control (1200 ppm group), ", $\mathrm{p}<0.05 ;{ }^{\#}, \mathrm{p}<0.01$. 
Reproductive toxicity study of dicyclohexyl phthalate.

Table 2. Food consumption.

\begin{tabular}{|c|c|c|c|c|c|}
\hline & Jnit : g/animal/day \\
\hline DCHP (ppm) & & 0 (Control) & 240 & 1200 & 6000 \\
\hline \multicolumn{6}{|l|}{ F0 males } \\
\hline & Pre-mating b & & & & \\
\hline & Day 7 & $19.0 \pm 1.3^{\mathrm{a}}$ & $19.6 \pm 0.8$ & $19.2 \pm 1.0$ & $19.2 \pm 1.3$ \\
\hline & Day 70 & $23.0 \pm 1.9$ & $23.3 \pm 1.2$ & $23.1 \pm 1.6$ & $23.1 \pm 1.7$ \\
\hline \multicolumn{6}{|l|}{ F0 females } \\
\hline \multicolumn{6}{|c|}{ Pre-mating } \\
\hline & Day 7 & $14.8 \pm 0.9$ & $15.1 \pm 1.0$ & $15.0 \pm 0.7$ & $14.7 \pm 1.2$ \\
\hline & Day 49 & $16.8 \pm 1.2$ & $16.7 \pm 1.0$ & $16.9 \pm 1.7$ & $15.5 \pm 1.2 *$ \\
\hline & Day 70 & $15.8 \pm 0.7$ & $15.8 \pm 1.1$ & $15.1 \pm 1.2$ & $14.9 \pm 0.7$ \\
\hline \multicolumn{6}{|c|}{ Gestation ${ }^{c}$} \\
\hline & GD 7 & $20.2 \pm 1.9$ & $20.1 \pm 1.7$ & $18.9 \pm 1.8$ & $18.0 \pm 1.7 * *$ \\
\hline & GD 14 & $22.0 \pm 2.6$ & $21.2 \pm 2.0$ & $20.4 \pm 1.5^{*}$ & $19.4 \pm 1.6^{* *}$ \\
\hline & GD 20 & $21.3 \pm 2.0$ & $21.3 \pm 2.4$ & $20.7 \pm 1.9$ & $20.8 \pm 1.9$ \\
\hline & Lactation $^{\mathrm{d}}$ & & & & \\
\hline & LD 4 & $26.6 \pm 4.0$ & $29.3 \pm 4.6$ & $30.2 \pm 4.6^{*}$ & $28.4 \pm 2.4$ \\
\hline & LD 21 & $66.2 \pm 4.3$ & $68.1 \pm 4.3$ & $69.8 \pm 5.5^{*}$ & $64.2 \pm 5.1$ \\
\hline \multicolumn{6}{|l|}{ F1 males } \\
\hline & Pre-mating & & & & \\
\hline & PND 28 & $11.7 \pm 0.8$ & $11.9 \pm 1.2$ & $11.4 \pm 0.8$ & $10.2 \pm 1.2 * *$ \\
\hline & PND 56 & $27.2 \pm 1.4$ & $27.1 \pm 2.0$ & $26.0 \pm 1.2$ & $24.6 \pm 1.4 * *$ \\
\hline & PND 91 & $27.2 \pm 1.6$ & $26.8 \pm 2.3$ & $25.1 \pm 0.7^{*}$ & $24.9 \pm 1.4^{*}$ \\
\hline \multicolumn{6}{|l|}{ F1 females } \\
\hline \multicolumn{6}{|c|}{ Pre-mating } \\
\hline & PND 28 & $10.2 \pm 1.1$ & $10.9 \pm 1.1$ & $10.6 \pm 1.1$ & $9.5 \pm 1.1$ \\
\hline & PND 56 & $16.9 \pm 1.4$ & $17.9 \pm 2.3$ & $17.1 \pm 1.9$ & $17.5 \pm 2.8$ \\
\hline & PND 91 & $17.0 \pm 1.2$ & $18.3 \pm 1.8$ & $17.8 \pm 0.9$ & $17.0 \pm 1.2$ \\
\hline \multicolumn{6}{|c|}{ Gestation } \\
\hline & GD 7 & $21.3 \pm 2.2$ & $21.7 \pm 2.4$ & $21.4 \pm 2.0$ & $20.0 \pm 2.1$ \\
\hline & GD 14 & $22.9 \pm 3.1$ & $23.5 \pm 2.3$ & $23.5 \pm 1.9$ & $21.2 \pm 2.0$ \\
\hline & GD 20 & $23.2 \pm 2.3$ & $23.6 \pm 2.4$ & $23.5 \pm 2.7$ & $22.4 \pm 2.0$ \\
\hline \multicolumn{6}{|c|}{ Lactation } \\
\hline & LD 4 & $29.0 \pm 3.3$ & $28.9 \pm 3.9$ & $28.4 \pm 4.3$ & $29.1 \pm 3.7$ \\
\hline & LD 21 & $71.6 \pm 5.5$ & $69.6 \pm 3.7$ & $70.6 \pm 5.1$ & $69.4 \pm 4.2$ \\
\hline
\end{tabular}

a: Mean \pm SD.

b: Pre-mating period (10 weeks).

c: Gestation length (Days 21-23).

d. Lactation period (Days 0-21).

GD: Gestation day.

LD: Lactation day.

PND: Postnatal day.

*: Significantly different from the control value, *, $\mathrm{p}<0.05 ; * *, \mathrm{p}<0.01$.

Table 3. Estrous cycle.

\begin{tabular}{|c|c|c|c|c|}
\hline DCHP (ppm) & 0 (Control) & 240 & 1200 & 6000 \\
\hline \multicolumn{5}{|l|}{ F0 females } \\
\hline No. of females examined & 24 & 24 & 24 & 24 \\
\hline Mean estrous cycle (days) & $4.04 \pm 0.14^{\mathrm{a}}$ & $4.06 \pm 0.22$ & $4.00 \pm 0.00$ & $4.25 \pm 0.42 *$ \\
\hline No. of females with abnormal estrous cycles ${ }^{b}$ & $0 / 24$ & $0 / 24$ & $0 / 24$ & $0 / 24$ \\
\hline \multicolumn{5}{|l|}{ F1 females } \\
\hline No. of females examined & 19 & 21 & 19 & 21 \\
\hline Mean estrous cycle (days) & $4.18 \pm 0.38$ & $4.14 \pm 0.32$ & $4.21 \pm 0.38$ & $4.33 \pm 0.46$ \\
\hline No. of females with abnormal estrous cycles & $1 / 20$ & $2 / 23$ & $0 / 20$ & $0 / 21$ \\
\hline
\end{tabular}

a: Mean \pm SD.

b: Number of the females with abnormal estrous cycle / number of the females examined.

*: Significantly different from the control value, *, $\mathrm{p}<0.05 ; * *, \mathrm{p}<0.01$. 
Table 4. Reproductive data.

\begin{tabular}{|c|c|c|c|c|}
\hline DCHP (ppm) & 0 (Control) & 240 & 1200 & 6000 \\
\hline \multicolumn{5}{|l|}{ F0 parents / F1 offspring } \\
\hline No. of pairs & 24 & 24 & 24 & 24 \\
\hline No. of days until copulation (days) ${ }^{b}$ & $2.3 \pm 1.3^{\mathrm{a}}$ & $2.0 \pm 1.4$ & $2.5 \pm 1.1$ & $2.1 \pm 1.2$ \\
\hline Mating index $(\%)^{c}$ & 91.7 & 95.8 & 91.7 & 95.8 \\
\hline Fertility index $(\%)^{d}$ & 90.9 & 100.0 & 90.9 & 95.7 \\
\hline Gestation length (days) ${ }^{\mathrm{e}}$ & $21.9 \pm 0.4$ & $22.0 \pm 0.6$ & $22.1 \pm 0.5$ & $21.9 \pm 0.3$ \\
\hline Gestation index $(\%)^{\mathrm{f}}$ & 100.0 & 100.0 & 100.0 & 100.0 \\
\hline Birth index $(\%)^{\mathrm{g}}$ & $95.85 \pm 4.68$ & $94.35 \pm 6.63$ & $94.73 \pm 10.01$ & $92.55 \pm 7.15$ \\
\hline No. of implantation sites & $14.4 \pm 2.5$ & $14.4 \pm 2.4$ & $14.6 \pm 2.2$ & $15.0 \pm 1.4$ \\
\hline Total No. of offspring at birth & $13.8 \pm 2.6$ & $13.9 \pm 2.6$ & $13.9 \pm 2.2$ & $14.0 \pm 1.6$ \\
\hline No. of offspring born alive & $13.8 \pm 2.6$ & $13.7 \pm 2.8$ & $13.8 \pm 2.2$ & $13.8 \pm 1.5$ \\
\hline Sex ratio ${ }^{h}$ & 0.49 & 0.50 & 0.49 & 0.52 \\
\hline \multicolumn{5}{|l|}{ Body weights of male offspring } \\
\hline Day 0 & $6.8 \pm 0.6$ & $6.8 \pm 0.5$ & $6.8 \pm 0.4$ & $6.5 \pm 0.4^{*}$ \\
\hline Day 4 & $11.3 \pm 1.2$ & $11.4 \pm 1.2$ & $11.5 \pm 1.2$ & $10.4 \pm 1.0 *$ \\
\hline Day 7 & $18.5 \pm 1.4$ & $18.7 \pm 1.6$ & $18.3 \pm 1.6$ & $16.7 \pm 1.3 * *$ \\
\hline Day 14 & $37.0 \pm 2.4$ & $37.2 \pm 2.6$ & $36.8 \pm 2.1$ & $33.4 \pm 2.0^{* *}$ \\
\hline Day 21 & $62.2 \pm 4.5$ & $61.9 \pm 4.8$ & $62.6 \pm 4.6$ & $55.0 \pm 3.8 * *$ \\
\hline \multicolumn{5}{|l|}{ Body weights of female offspring } \\
\hline Day 0 & $6.5 \pm 0.5$ & $6.4 \pm 0.5$ & $6.4 \pm 0.5$ & $6.1 \pm 0.4^{*}$ \\
\hline Day 4 & $10.9 \pm 1.1$ & $11.1 \pm 1.2$ & $11.0 \pm 1.2$ & $9.8 \pm 1.1 * *$ \\
\hline Day 7 & $17.8 \pm 1.3$ & $18.0 \pm 1.7$ & $17.5 \pm 1.7$ & $15.9 \pm 1.5 * *$ \\
\hline Day 14 & $35.9 \pm 2.1$ & $36.2 \pm 3.0$ & $35.5 \pm 2.3$ & $32.0 \pm 2.0 * *$ \\
\hline Day 21 & $59.2 \pm 3.7$ & $59.6 \pm 4.9$ & $59.4 \pm 4.7$ & $52.8 \pm 3.2 * *$ \\
\hline \multicolumn{5}{|l|}{ F1 parents / F2 offspring } \\
\hline No. of pairs & 20 & 23 & 20 & 21 \\
\hline No. of days until copulation (days) & $3.2 \pm 1.2$ & $2.5 \pm 1.5$ & $1.9 \pm 1.2^{* *}$ & $2.9 \pm 2.3$ \\
\hline Mating index $(\%)$ & 95.0 & 100.0 & 100.0 & 90.5 \\
\hline Fertility index (\%) & 100.0 & 95.7 & 95.0 & 89.5 \\
\hline Gestation length (days) & $21.9 \pm 0.2$ & $21.9 \pm 0.4$ & $21.7 \pm 0.5$ & $22.0 \pm 0.5$ \\
\hline Gestation index $(\%)$ & 100.0 & 100.0 & 100.0 & 100.0 \\
\hline Birth index $(\%)$ & $90.91 \pm 6.11$ & $92.85 \pm 6.55$ & $94.46 \pm 6.66$ & $93.55 \pm 8.22$ \\
\hline No. of implantation sites & $15.9 \pm 2.1$ & $15.5 \pm 1.6$ & $14.9 \pm 2.6$ & $14.3 \pm 2.9$ \\
\hline Total No. of offspring at birth & $14.6 \pm 2.2$ & $14.7 \pm 1.6$ & $14.2 \pm 2.6$ & $13.9 \pm 2.9$ \\
\hline No. of offspring born alive & $14.5 \pm 2.3$ & $14.4 \pm 1.5$ & $14.1 \pm 2.6$ & $13.3 \pm 2.5$ \\
\hline Sex ratio & 0.51 & 0.50 & 0.48 & 0.51 \\
\hline \multicolumn{5}{|l|}{ Body weights of male offspring } \\
\hline Day 0 & $6.8 \pm 0.4$ & $6.6 \pm 0.5$ & $6.5 \pm 0.5$ & $6.6 \pm 0.6$ \\
\hline Day 4 & $11.1 \pm 0.9$ & $11.0 \pm 1.0$ & $10.9 \pm 1.0$ & $11.1 \pm 1.8$ \\
\hline Day 7 & $18.4 \pm 1.3$ & $18.1 \pm 1.5$ & $17.8 \pm 1.6$ & $18.3 \pm 2.2$ \\
\hline Day 14 & $38.5 \pm 2.2$ & $37.8 \pm 2.5$ & $37.3 \pm 2.7$ & $36.2 \pm 2.9$ \\
\hline Day 21 & $64.9 \pm 4.2$ & $62.8 \pm 4.2$ & $62.8 \pm 5.0$ & $59.2 \pm 5.0 * *$ \\
\hline \multicolumn{5}{|l|}{ Body weights of female offspring } \\
\hline Day 0 & $6.4 \pm 0.4$ & $6.2 \pm 0.4$ & $6.2 \pm 0.5$ & $6.2 \pm 0.6$ \\
\hline Day 4 & $10.6 \pm 0.7$ & $10.5 \pm 0.8$ & $10.4 \pm 1.2$ & $10.6 \pm 1.5$ \\
\hline Day 7 & $17.6 \pm 1.0$ & $17.2 \pm 1.3$ & $16.9 \pm 1.9$ & $17.5 \pm 1.9$ \\
\hline Day 14 & $37.3 \pm 2.1$ & $36.3 \pm 2.2$ & $35.8 \pm 2.7$ & $35.0 \pm 2.6$ \\
\hline Day 21 & $61.7 \pm 3.7$ & $59.3 \pm 3.5$ & $59.2 \pm 4.4$ & $56.6 \pm 4.3 * *$ \\
\hline
\end{tabular}

a: Mean \pm SD.

b: No. of days until copulation (days) = Number of days from the start of the mating until the day of copulation confirmed.

c: Mating index $(\%)=$ (Number of males and females showing evidence of copulation / number of males and females used for mating) $\times 100$.

d: Fertility index $(\%)=($ Number of pregnant females / number of copulated females $) \times 100$.

e: Gestation length (days) = Number of days from GD 0 till the delivery day.

f: Gestation index $(\%)=($ Number of females with normal delivery / number of pregnant females $) \times 100$.

$\mathrm{g}$ : Birth index $(\%)=($ Number of live pups delivered / number of implantations $) \times 100$.

h: Sex ratio $=$ Total number of male pups delivered $/$ total number of pups delivered.

*: Significantly different from the control value, *, $\mathrm{p}<0.05 ; * *, \mathrm{p}<0.01$. 
Reproductive toxicity study of dicyclohexyl phthalate.

mal, and examination for this rat revealed no sperm.

\section{5) Serum hormone levels}

Data for serum hormone levels in F0 and F1 parental animals are shown in Table 5. Changes with statistical significance included elevated testosterone in F0 parental males of the $1200 \mathrm{ppm}$ group and the lowered FSH in F1 parental females in the 240 ppm

Table 5. Data from sperm parameters and hormone levels.

\begin{tabular}{|c|c|c|c|c|c|c|c|c|c|}
\hline \multirow{2}{*}{$\begin{array}{l}\text { DCHP }(\mathrm{ppm}) \\
\text { F0 parents }\end{array}$} & \multicolumn{2}{|c|}{0 (Control) } & \multicolumn{2}{|l|}{240} & \multicolumn{2}{|c|}{1200} & \multicolumn{3}{|c|}{6000} \\
\hline & & & & & & & & & \\
\hline \multicolumn{10}{|l|}{ Sperm examination } \\
\hline No. of males examined & \multicolumn{2}{|c|}{10} & \multicolumn{2}{|l|}{10} & \multicolumn{2}{|l|}{10} & \multicolumn{3}{|c|}{10} \\
\hline Sperm motility $(\%)$ & 90.7 & $4.81^{\mathrm{a}}$ & $89.1 \pm$ & 5.95 & $87.9 \pm$ & 6.45 & $87.4=$ & \pm & 7.71 \\
\hline $\begin{array}{r}\text { Homogenization-resistant spermatids }\left(\times 10^{6} / \mathrm{g}\right) \\
\text { (spermatid head counts in the testis) }\end{array}$ & 110.6 & 9.02 & - & & - & & $104.8=$ & \pm & 9.34 \\
\hline Sperm count $\left(\times 10^{6} / \mathrm{g}\right)$, (cauda epididymal) & 766.5 & \pm 102.77 & - & & - & & $745.0=$ & \pm & 87.98 \\
\hline Abnormal sperm (\%) & 0.5 & 0.47 & - & & - & & $1.0=$ & \pm & 0.96 \\
\hline Tailless sperm $(\%)$ & 0.6 & 0.70 & - & & - & & $1.2=$ & \pm & 1.23 \\
\hline \multicolumn{10}{|l|}{ Hormone levels } \\
\hline No. of males examined & & 6 & 6 & & 6 & & & 6 & \\
\hline Testosterone (ng/mL) & 1.92 & 0.75 & $2.59 \pm$ & 0.45 & $3.45 \pm$ & $0.74 *$ & $2.04=$ & \pm & 0.87 \\
\hline FSH (ng/mL) & 9.88 & 1.05 & $10.57 \pm$ & 1.54 & $9.67 \pm$ & 1.05 & $9.60 \pm$ & \pm & 1.37 \\
\hline $\mathrm{LH}(\mathrm{ng} / \mathrm{mL})$ & 1.82 & 0.17 & $1.88 \pm$ & 0.13 & $1.88 \pm$ & 0.20 & $1.97 \pm$ & \pm & 0.23 \\
\hline No. of females examined & & 6 & 6 & & 6 & & & 6 & \\
\hline FSH (ng/mL) & 6.47 & 0.69 & $5.99 \pm$ & 1.04 & $6.71 \pm$ & 0.68 & $6.27 \pm$ & \pm & 0.67 \\
\hline $\mathrm{LH}(\mathrm{ng} / \mathrm{mL})$ & 2.02 & 0.25 & $1.85 \pm$ & 0.31 & $1.92 \pm$ & 0.20 & $2.02 \pm$ & \pm & 0.09 \\
\hline Estradiol (pg/mL) & 72.85 & \pm 23.06 & $72.22 \pm$ & 24.30 & $72.25 \pm$ & 17.60 & $81.25 \pm$ & \pm & 13.76 \\
\hline
\end{tabular}

F1 parents

Sperm examination

No. of males examined

Sperm motility (\%)

10

$90.7 \pm 4.45 \quad 92.8 \pm 3.55$

10

10

Homogenization-resistant spermatids $\left(\times 10^{6} / \mathrm{g}\right)$

$104.0 \pm 12.66$

$93.4 \pm 10.27$

$88.7 \pm$ (spermatid head counts in the testis)

$-$

Sperm count $\left(\times 10^{6} / \mathrm{g}\right)$, (cauda epididymal)

$728.4 \pm 88.07$

Abnormal sperm (\%)

$0.2 \pm 0.26$

$0.6 \pm 0.70$

$-$

Tailless sperm (\%)

Hormone levels
No. of males examined

6

$2.05 \pm 0.75$

$8.98 \pm 1.32$

$2.11 \pm 0.24$

5

$\mathrm{LH}(\mathrm{ng} / \mathrm{mL})$

No. of females examined

FSH (ng/mL)

LH (ng/mL)

Estradiol $(\mathrm{pg} / \mathrm{mL})$
$8.80 \pm \quad 3.10 \quad 5.50 \pm 0.65^{*}$

$1.58 \pm 0.90$ $51.28 \pm 38.86$

$\begin{array}{rr}6 & \\ 2.38 \pm & 1.05 \\ 10.41 \pm & 2.96 \\ 2.00 \pm & 0.24 \\ 6 & \\ 5.50 \pm & 0.65^{*} \\ 1.99 \pm & 0.35 \\ 82.53 \pm & 13.24\end{array}$

$2.74 \pm \quad 1.24$

$10.08 \pm 1.40$

$2.03 \pm 0.29$

6

$6.27 \pm 0.94$

$1.99 \pm 0.14$

$59.25 \pm 15.13$

$$
\begin{aligned}
599.7 & \pm 219.22 \\
0.3 & \pm 0.36 \\
0.8 & \pm \\
&
\end{aligned}
$$

a: Mean \pm SD.

*: Significantly different from the control value, *, $\mathrm{p}<0.05 ; * *, \mathrm{p}<0.01$.

-: Not examined. 


\section{N. HOSHINO et al.}

group. However, since changes were not evident at $6000 \mathrm{ppm}$, they were not considered related to DCHP.

\section{6) Organ Weights}

Organ weights for F0 and F1 parental animals are shown in Table 6. In the 6000 ppm group, significant increase in relative liver weights in F0 parental males and females and of thyroid in F0 parental males was noted. In addition, regarding the corresponding absolute organ weights, tendencies for increase were appar-

Table 6. Organ weights for F0/F1 adults.

\begin{tabular}{|c|c|c|c|c|c|c|c|c|}
\hline \multirow{2}{*}{$\begin{array}{l}\text { DCHP (ppm) } \\
\text { F0 adults }\end{array}$} & \multicolumn{2}{|c|}{0 (Control) } & \multicolumn{2}{|c|}{240} & \multicolumn{2}{|c|}{1200} & \multicolumn{2}{|c|}{6000} \\
\hline & & & & & & & & \\
\hline No. of male F0 adults examined & & 24 & & 24 & & 24 & & 24 \\
\hline Final body weight $(\mathrm{g})$ & 510.5 & $\pm 50.4^{\mathrm{a}}$ & 503.6 & \pm 42.5 & 500.4 & \pm 28.0 & 496.7 & \pm 37.1 \\
\hline \multirow[t]{2}{*}{ Thyroid (L), (mg) } & 11.33 & $\pm 2.65^{b}$ & 12.48 & \pm 2.47 & 11.99 & \pm 2.11 & 14.37 & $\pm 4.02 * *$ \\
\hline & 2.23 & $\pm 0.51^{\mathrm{c}}$ & 2.48 & \pm 0.46 & 2.40 & \pm 0.43 & 2.91 & $\pm 0.91 * *$ \\
\hline \multirow[t]{2}{*}{ Thyroid (R), (mg) } & 11.74 & \pm 2.54 & 11.80 & \pm 2.14 & 12.31 & \pm 3.01 & 12.63 & \pm 2.79 \\
\hline & 2.33 & \pm 0.51 & 2.35 & \pm 0.42 & 2.46 & \pm 0.58 & 2.54 & \pm 0.50 \\
\hline \multirow[t]{2}{*}{ Liver $(\mathrm{g})$} & 15.042 & \pm 1.911 & 14.620 & \pm 1.960 & 14.596 & \pm 1.183 & 18.157 & $\pm 1.730 * *$ \\
\hline & 2.944 & \pm 0.203 & 2.898 & \pm 0.229 & 2.917 & \pm 0.177 & 3.658 & $\pm 0.252 * *$ \\
\hline \multirow[t]{2}{*}{ Prostate $(\mathrm{g})$} & 0.712 & \pm 0.144 & 0.640 & \pm 0.140 & 0.642 & \pm 0.173 & 0.657 & \pm 0.155 \\
\hline & 0.141 & \pm 0.032 & 0.127 & \pm 0.024 & 0.128 & \pm 0.034 & 0.134 & \pm 0.039 \\
\hline No. of female F0 adults examined & \multicolumn{2}{|c|}{20} & \multicolumn{2}{|c|}{23} & \multicolumn{2}{|c|}{20} & \multicolumn{2}{|r|}{22} \\
\hline Final body weight (g) & 322.1 & \pm 19.7 & 311.9 & \pm 16.6 & 306.5 & $\pm 18.2^{*}$ & 295.3 & $\pm 18.8^{* *}$ \\
\hline \multirow[t]{2}{*}{ Thyroid (L), (mg) } & 10.08 & \pm 2.15 & 9.74 & \pm 1.59 & 9.91 & \pm 1.80 & 11.35 & \pm 1.39 \\
\hline & 3.13 & \pm 0.68 & 3.12 & \pm 0.49 & 3.23 & \pm 0.57 & 3.87 & $\pm 0.54 * *$ \\
\hline \multirow[t]{2}{*}{ Thyroid (R), (mg) } & 11.13 & \pm 2.46 & 11.14 & \pm 1.90 & 10.78 & \pm 2.16 & 11.89 & \pm 2.18 \\
\hline & 3.54 & \pm 0.81 & 3.58 & \pm 0.59 & 3.54 & \pm 0.69 & 4.06 & $\pm 0.83^{*}$ \\
\hline \multirow[t]{2}{*}{ Liver (g) } & 10.233 & \pm 0.994 & 9.907 & \pm 0.772 & 10.298 & \pm 0.824 & 11.157 & $\pm 0.995^{* *}$ \\
\hline & 3.174 & \pm 0.168 & 3.176 & \pm 0.171 & 3.362 & $\pm 0.190 *$ & 3.779 & $\pm 0.251 * *$ \\
\hline \multicolumn{9}{|l|}{ F1 adults } \\
\hline \multirow{2}{*}{$\begin{array}{l}\text { No. of male F1 adults examined } \\
\text { Final body weight }(\mathrm{g})\end{array}$} & \multicolumn{2}{|r|}{20} & \multicolumn{2}{|r|}{23} & \multicolumn{2}{|r|}{20} & \multicolumn{2}{|r|}{21} \\
\hline & 624.9 & \pm 48.9 & 603.4 & \pm 54.0 & 564.7 & $\pm 42.0 * *$ & 552.5 & $\pm 30.5^{* *}$ \\
\hline \multirow[t]{2}{*}{ Thyroid (L), (mg) } & $15.11=$ & \pm 2.23 & 13.55 & \pm 3.30 & 14.24 & \pm 4.41 & 15.06 & \pm 2.77 \\
\hline & $2.43=$ & \pm 0.46 & 2.28 & \pm 0.65 & 2.52 & \pm 0.72 & 2.72 & \pm 0.48 \\
\hline \multirow[t]{2}{*}{ Thyroid (R), (mg) } & $16.17=$ & \pm 3.34 & 14.24 & \pm 3.40 & 13.61 & $\pm 2.44 *$ & 15.66 & \pm 2.68 \\
\hline & $2.62=$ & \pm 0.62 & 2.38 & \pm 0.67 & 2.42 & \pm 0.49 & 2.84 & \pm 0.46 \\
\hline Liver (g) & 18.822 & \pm 2.402 & 17.374 & \pm 2.137 & 16.609 & $\pm 1.691 * *$ & 18.953 & \pm 2.371 \\
\hline & 3.004 & \pm 0.210 & 2.877 & \pm 0.195 & 2.943 & \pm 0.238 & 3.423 & $\pm 0.314 * *$ \\
\hline Prostate $(\mathrm{g})$ & 0.707 & \pm 0.152 & 0.575 & $\pm 0.133^{*} *$ & 0.593 & $\pm 0.149 *$ & 0.508 & $\pm 0.118^{* *}$ \\
\hline & 0.114 & \pm 0.027 & 0.096 & \pm 0.020 & 0.106 & \pm 0.029 & 0.092 & $\pm 0.024^{*}$ \\
\hline No. of female $\mathrm{F} 1$ adults examined & & 19 & & 22 & & 19 & & 17 \\
\hline Final body weight (g) & 337.4 & \pm 27.8 & 338.7 & \pm 23.9 & 330.8 & \pm 18.8 & 320.7 & \pm 22.7 \\
\hline Thyroid (L), (mg) & $12.32=$ & \pm 3.48 & 11.35 & \pm 1.91 & 12.07 & \pm 2.30 & 11.79 & \pm 2.55 \\
\hline & $3.66=$ & \pm 1.05 & 3.36 & \pm 0.62 & 3.66 & \pm 0.74 & 3.69 & \pm 0.85 \\
\hline Thyroid (R), (mg) & $14.46=$ & \pm 2.92 & 12.47 & \pm 2.53 & 13.33 & \pm 2.79 & 13.71 & \pm 3.16 \\
\hline & $4.31=$ & \pm 0.87 & 3.69 & \pm 0.80 & 4.05 & \pm 0.91 & 4.28 & \pm 1.05 \\
\hline Liver $(\mathrm{g})$ & $12.772=$ & \pm 1.844 & 12.326 & \pm 1.459 & 12.907 & \pm 1.697 & 14.102 & \pm 1.918 \\
\hline & $3.784=$ & \pm 0.455 & 3.640 & \pm 0.360 & 3.902 & \pm 0.467 & 4.385 & $\pm 0.393^{* *}$ \\
\hline
\end{tabular}

a: Mean \pm SD.

b: Absolute organ weight.

c: Relative organ weight.

*: Significantly different from the control value, *, $\mathrm{p}<0.05 ; * *, \mathrm{p}<0.01$. 
Reproductive toxicity study of dicyclohexyl phthalate.

ent. Significant lowering of values was observed for both absolute and relative prostatic weights in F1 parental males in the same group. In the 240 and 1200 ppm groups, no obvious changes were observed in either F0 or F1 males or females.

\section{7) Pathological and histopathological findings}

As necropsy findings, enlargement of the liver was observed in F0 and F1 parental males and females of the $6000 \mathrm{ppm}$ group and in F1 parental females of the $1200 \mathrm{ppm}$ group. Soft small sized testes were observed in F1 males in the 6000 ppm group.

Data for histopathological findings in F0 and F1 parental animals are shown in Table 7. On examination of the reproductive organs, in F0 parental males, focal atrophy of seminiferous tubules was noted in one each of the control and $6000 \mathrm{ppm}$ groups, and no difference in the status was observed. In F1 parental males, three animals in the 6000 ppm group showed diffuse atrophy of seminiferous tubules; along with focal atrophy one in the control, two in the 1200 ppm, and six in the 6000 ppm group. Moreover, in the 6000 ppm group, increase in the degree of atrophic testicular changes was revealed. A lack of sperm in the epididymal tubes was observed in the three males with diffusely atrophic seminiferous tubules.

Histopathological examination revealed diffuse hypertrophy of hepatocytes in F0 males and females of the 1200 ppm or higher groups, and in F1 males and females of the $6000 \mathrm{ppm}$ group. Hypertrophy of the thyroid follicular cells was observed in F0 males of the 1200 ppm or higher groups, F0 females of the 6000 ppm group, and F1 males and females of the $6000 \mathrm{ppm}$ group. Hypertrophied follicular epithelial cells appeared to be high-columnar, and follicles lined with such cells containing small amounts of colloid. While the shape of normal follicular antrum was almost circular, that lined by hypertrophic cells appeared to be irregular.

Increased hyaline droplets in the renal proximal

Table 7. Histopathological findings for F0/F1 adults.

\begin{tabular}{|c|c|c|c|c|c|c|c|c|c|}
\hline \multirow{2}{*}{ DCHP (ppm) } & \multicolumn{5}{|c|}{ Male } & \multicolumn{4}{|c|}{ Female } \\
\hline & & 0 (Control) & 240 & 1200 & 6000 & 0 (Control) & 240 & 1200 & 6000 \\
\hline \multicolumn{10}{|l|}{ F0 adults } \\
\hline No. of F0 adults examined & & 24 & 24 & 24 & 24 & 24 & 24 & 24 & 24 \\
\hline \multicolumn{10}{|l|}{ Liver } \\
\hline Hypertrophy, hepatocytes, diffuse & + & 0 & 0 & 4 & 16 & 0 & 0 & 3 & 12 \\
\hline \multicolumn{10}{|l|}{ Thyroid } \\
\hline Hypertrophy, follicular cells & + & 0 & 0 & 3 & 7 & 0 & 0 & 0 & 6 \\
\hline \multicolumn{10}{|l|}{ Kidney } \\
\hline \multirow{2}{*}{ Hyaline droplet, tubular epithelium, proximal } & + & 23 & 22 & 23 & 9 & 0 & - & $0 / 1^{a}$ & 0 \\
\hline & ++ & 1 & 1 & 0 & 15 & 0 & - & $0 / 1$ & 0 \\
\hline \multicolumn{10}{|l|}{ F1 adults } \\
\hline \multicolumn{9}{|l|}{ Liver } & 22 \\
\hline Hypertrophy, hepatocytes, diffuse & + & 0 & 0 & 0 & 14 & 0 & 0 & 0 & 9 \\
\hline \multicolumn{10}{|l|}{ Thyroid } \\
\hline Hypertrophy, follicular cells & + & 0 & 0 & 0 & 7 & 0 & 0 & 0 & 6 \\
\hline \multicolumn{10}{|l|}{ Kidney } \\
\hline \multirow[t]{2}{*}{ Hyaline droplet, tubular epithelium, proximal } & + & 19 & 22 & 20 & 14 & 0 & - & - & 0 \\
\hline & ++ & 1 & 1 & 0 & 8 & 0 & - & - & 0 \\
\hline \multicolumn{10}{|l|}{ Testis } \\
\hline Atrophy, seminiferous tubules, diffuse & +++ & 0 & 0 & 0 & 3 & & & & \\
\hline Atrophy, seminiferous tubules, focal & + & 1 & 0 & 2 & 6 & & & & \\
\hline
\end{tabular}

+, Slight; ++, Moderate; +++, Severe.

a: Number of animals affected / number of the animal examined.

-: Not examined. 
tubular epithelium were observed in both F0 and F1 parental males in the 6000 ppm group. Marked change (moderate grade) of the increased hyaline droplet accompanied with the appearance of eosinophilic microbodies. Moderately increased hyaline droplets were also observed in one each of the F0 and F1 males of the control and 240 ppm groups, however, increase in the number of the cases with hyaline droplet was shown in the cases with moderate grade in the 6000 ppm group.

\section{Effects on the growth and development of the off- spring 1) Clinical signs and body weight}

In the F1 and F2 offspring, no changes related to DCHP treatment were found for clinical signs in any dose group. With 6000 ppm, significantly lowered values were found as follows: for body weights on PNDs 0-21 in males and females, for body weight gain on PNDs 7-21 in males and PNDs 4-21 in females in the F1 offspring, and for body weights on PND 21 and for body weight gain on PNDs 14-21 in males and females in the F2 offspring.

\section{2) AGD and areola examination}

Data for AGD and areolae in F1 and F2 pups are shown in Table 8 . In the F1 and F2 male offspring of animal receiving $6000 \mathrm{ppm}$, significantly lower values were observed in anogenital distance (AGD) and the relative AGD values and the appearance of the areola was also observed. In the F2 male offspring in 1200 ppm group, reduced absolute and relative AGD and appearance of the areolae were also observed.

\section{3) Viability index and physical development}

Viability indices and values for physical development parameter in F1 and F2 pups are shown in Table 9. There were no changes in the $240 \mathrm{ppm}$ group. No change related to DCHP treatment was observed in any dose group in terms of the number of F1 and F2 pups delivered, viability on PNDs 0,4 , and 21 , the results of the reflex response tests and external surface anomalies. There were no DCHP treatment-related changes observed in terms of the incidence of pinna unfolding, the ages of incisor eruption (upper incisor eruption) and eye opening in both males and females of the F1 and F2 offspring, the ages as well as body weights at vaginal opening in F1 female offspring and at preputial separation in F1 male offspring. Although F1 male offspring in the $6000 \mathrm{ppm}$ group showed significantly lowered body weights on the day of preputial separation, the age was not statistically different from that of control, and body weight gain of the group was inhibited throughout after PND 0. Thus, it was considered that the test substance did not directly affect sexual maturation of the offspring in spite of the body weight gain inhibition.

\section{4) Organ weights}

Organ weights for F1 and F2 offsprings are shown in Table 10. In the $6000 \mathrm{ppm}$ group, significant changes in thymus, spleen and brain weights were observed. These changes, however, were found only in either absolute or relative weights, and some showed contrary results between the two. Therefore, it was considered that the changes were attributable to inhibition of body weight gain, which was related to administration of DCHP. In the groups receiving doses of 1200 ppm or less, no test substance related changes were observed.

\section{5) Necropsy findings}

Dilatation of the renal pelvis was observed in F1 male or female offspring of the control and treated groups. However, these changes appeared in only one or two animals and were not dose-dependent, so they were considered to be unrelated to DCHP. In addition, no abnormalities were observed in the one F2 offspring which died during the lactational period.

\section{DISCUSSION}

The toxic effects found in F0 and F1 parental animals in the present study were as follows: inhibition of body weight gain and food consumption, diffuse hypertrophy of hepatocytes and of thyroidal follicular cells in the 1200 ppm or 6000 ppm groups; increased organ weights of the liver and thyroid, and increased hyaline droplets in the renal proximal tubular epithelium (male animals only) were additionally observed at 6000 ppm. Furthermore, decrease in prostate weights and diffuse and/or focal atrophy of testicular seminiferous tubules were observed in F1 males of the $6000 \mathrm{ppm}$ group. In F1 and F2 offspring, inhibition of body weight gain in both sexes of the 6000 ppm group was observed.

Endocrine disrupting effects on the F1 and F2 offspring included the following: decrease in the anogenital distance (AGD) and the appearance of areolae in F1 males of the $6000 \mathrm{ppm}$ group and F2 males at $1200 \mathrm{ppm}$ and $6000 \mathrm{ppm}$. Detailed examination revealed no female-type nipples, and areolae were 
Reproductive toxicity study of dicyclohexyl phthalate.

observed only. Thus, the degree of the effect was not severe. It had been reported that with decrease in AGD and the appearance of nipples in male offspring may occur administration of phthalate esters like the test substance (Gray et al., 2001). For example di-n-butyl phthalate (DBP) showed anti-androgenic activity estimated to be caused not by an androgen receptor (AR) mediated mechanism, but rather by inhibition of testosterone synthesis in the fetus (Shultz et al., 2001). Accordingly, we concluded that DCHP induced the decrease of AGD and the appearance of areola in male offspring through a similar mechanism. Our data suggest that DCHP might exert endocrine disrupting effects in male animals of the next generation because changes in the endocrine system were recognized in F1 male offspring of the 6000 ppm group and F2 male offspring at $1200 \mathrm{ppm}$ and $6000 \mathrm{ppm}$ under the conditions of this study.

Atrophy of the seminiferous tubules in the testis was observed in 9 of $22 \mathrm{~F} 1$ males of the $6000 \mathrm{ppm}$ group. Three showed diffuse atrophy, with marked testicular atrophic change. It is known that atrophy of

Table 8. Anogenital distance and nipple development.

\begin{tabular}{|c|c|c|c|c|c|}
\hline DCHP (ppm) & & 0 (Control) & 240 & 1200 & 6000 \\
\hline \multicolumn{6}{|l|}{ F1 pups } \\
\hline No. of males examined & & 20 & 23 & 20 & 22 \\
\hline $\operatorname{AGD}^{b}(\mathrm{~mm})^{\mathrm{c}}$ & & $4.683 \pm 0.522^{\mathrm{a}}$ & $4.860 \pm 0.491$ & $4.757 \pm 0.448$ & $4.373 \pm 0.354^{* *}$ \\
\hline AGD/BW 1/3 d & & $2.171 \pm 0.216$ & $2.162 \pm 0.213$ & $2.107 \pm 0.148$ & $2.003 \pm 0.151^{*}$ \\
\hline \multirow[t]{3}{*}{ Nipple development (\%) ${ }^{\mathrm{e}}$} & 0 & 100.0 & 100.0 & 100.0 & $83.3 * *$ \\
\hline & 1 & 0.0 & 0.0 & 0.0 & $16.1 * *$ \\
\hline & 2 & 0.0 & 0.0 & 0.0 & 0.0 \\
\hline No. of females examined & & 20 & 23 & 20 & 22 \\
\hline AGD (mm) & & $2.237 \pm 0.297$ & $2.355 \pm 0.249$ & $2.323 \pm 0.310$ & $2.226 \pm 0.150$ \\
\hline AGD/BW 1/3 & & $1.013 \pm 0.141$ & $1.059 \pm 0.117$ & $1.045 \pm 0.114$ & $1.042 \pm 0.075$ \\
\hline \multirow[t]{3}{*}{ Nipple development (\%) } & 0 & 100.0 & 100.0 & 100.0 & 100.0 \\
\hline & 1 & 0.0 & 0.0 & 0.0 & 0.0 \\
\hline & 2 & 0.0 & 0.0 & 0.0 & 0.0 \\
\hline \multicolumn{6}{|l|}{ F2 pups } \\
\hline No. of males examined & & 19 & 22 & 19 & 17 \\
\hline $\mathrm{AGD}(\mathrm{mm})$ & & $4.618 \pm 0.314$ & $4.494 \pm 0.300$ & $4.281 \pm 0.365^{* *}$ & $4.191 \pm 0.387^{* *}$ \\
\hline AGD/BW ${ }^{1 / 3}$ & & $2.072 \pm 0.152$ & $2.020 \pm 0.125$ & $1.932 \pm 0.158 * *$ & $1.882 \pm 0.129 * *$ \\
\hline \multirow[t]{3}{*}{ Nipple development (\%) } & 0 & 100.0 & 100.0 & 81.6 & $36.8 * *$ \\
\hline & 1 & 0.0 & 0.0 & 18.4 & $63.2 * *$ \\
\hline & 2 & 0.0 & 0.0 & 0.0 & 0.0 \\
\hline No. of females examined & & 19 & 22 & 19 & 17 \\
\hline AGD (mm) & & $2.066 \pm 0.157$ & $2.125 \pm 0.161$ & $2.060 \pm 0.169$ & $2.188 \pm 0.236$ \\
\hline AGD/BW 1/3 & & $0.943 \pm 0.072$ & $0.972 \pm 0.063$ & $0.946 \pm 0.062$ & $0.998 \pm 0.075$ \\
\hline \multirow[t]{3}{*}{ Nipple development (\%) } & 0 & 100.0 & 100.0 & 100.0 & 100.0 \\
\hline & 1 & 0.0 & 0.0 & 0.0 & 0.0 \\
\hline & 2 & 0.0 & 0.0 & 0.0 & 0.0 \\
\hline
\end{tabular}

a: Mean \pm SD.

b: AGD was measured on PND (postnatal day) 4.

c: Distance between the anus and genital node ( $\mathrm{mm})$.

d: The relative AGD value divided by cubic root of the body weight on the measurement day was also calculated.

e: Number of litters with abnormal offspring / number of litters examined $\times 100$.

0 : Nipple development "0" ; No abnormality.

1: Nipple development "1" ; Presence of areole mammae with no nipple.

2: Nipple development "2" ; Male, Presence of nipple. Female, Absence of nipple.

*: Significantly different from the control value, $*, \mathrm{p}<0.05 ; * *, \mathrm{p}<0.01$. 
N. HOSHINO et al.

Table 9. Viability indices and parameter for physical development and sexual maturation.

\begin{tabular}{|c|c|c|c|c|}
\hline DCHP (ppm) & 0 (Control) & 240 & 1200 & 6000 \\
\hline \multicolumn{5}{|l|}{ F1 pups } \\
\hline \multicolumn{5}{|l|}{ Viability index (\%) } \\
\hline Day $0^{\mathrm{b}}$ & $100.00 \pm 0.00^{\mathrm{a}}$ & $98.08 \pm 3.87$ & $99.25 \pm 2.37$ & $98.78 \pm 2.67$ \\
\hline Day $4^{c}$ & $98.93 \pm 2.70$ & $99.09 \pm 2.42$ & $99.65 \pm 1.59$ & $98.86 \pm 5.33$ \\
\hline Day $21^{\mathrm{d}}$ & $100.00 \pm 0.00$ & $100.00 \pm 0.00$ & $100.00 \pm 0.00$ & $100.00 \pm 0.00$ \\
\hline \multicolumn{5}{|l|}{ Physical development } \\
\hline \multicolumn{5}{|l|}{ Pinna unfolding (\%) } \\
\hline No. of males examined & 20 & 23 & 20 & 22 \\
\hline Day 2 & $21.2 \pm 27.7$ & $34.2 \pm 39.0$ & $37.2 \pm 39.1$ & $22.1 \pm 24.0$ \\
\hline Day 3 & $87.1 \pm 32.4$ & $86.6 \pm 30.8$ & $96.7 \pm 14.9$ & $92.0 \pm 26.0$ \\
\hline Day 4 & $99.3 \pm 3.2$ & $98.9 \pm 3.9$ & $100.0 \pm 0.0$ & $100.0 \pm 0.0$ \\
\hline No. of females examined & 20 & 23 & 20 & 22 \\
\hline Day 2 & $31.1 \pm 33.9$ & $33.6 \pm 37.8$ & $44.3 \pm 39.5$ & $20.3 \pm 23.0$ \\
\hline Day 3 & $87.9 \pm 30.1$ & $89.5 \pm 27.7$ & $93.8 \pm 22.8$ & $92.7 \pm 24.3$ \\
\hline Day 4 & $100.0 \pm 0.0$ & $100.0 \pm 0.0$ & $100.0 \pm 0.0$ & $100.0 \pm 0.0$ \\
\hline Incisor Eruption & & & & \\
\hline No. of males examined & 20 & 23 & 20 & 22 \\
\hline Age (day) ${ }^{\mathrm{e}}$ & $10.7 \pm 0.6$ & $10.8 \pm 0.9$ & $10.4 \pm 0.8$ & $10.5 \pm 0.8$ \\
\hline No. of females examined & 20 & 23 & 20 & 22 \\
\hline Age (day) & $10.8 \pm 0.8$ & $10.8 \pm 0.9$ & $10.4 \pm 0.8$ & $10.5 \pm 0.9$ \\
\hline Eye opening & & & & \\
\hline No. of males examined & 20 & 23 & 20 & 22 \\
\hline Age (day) & $14.0 \pm 0.6$ & $13.8 \pm 0.7$ & $13.9 \pm 0.6$ & $14.1 \pm 0.4$ \\
\hline No. of females examined & 20 & 23 & 20 & 22 \\
\hline Age (day) & $13.8 \pm 0.6$ & $13.6 \pm 0.8$ & $13.6 \pm 0.5$ & $13.9 \pm 0.5$ \\
\hline Sexual maturation & & & & \\
\hline Preputial separation (Male) & 20 & 23 & 20 & 22 \\
\hline Age (day) & $40.6 \pm 1.0$ & $40.6 \pm 1.2$ & $40.0 \pm 0.9$ & $41.4 \pm 1.6$ \\
\hline Body weight $(g)^{f}$ & $225.3 \pm 17.3$ & $225.1 \pm 12.5$ & $218.9 \pm 15.4$ & $212.5 \pm 13.8^{*}$ \\
\hline Vaginal opening (Female) & 20 & 23 & 20 & 21 \\
\hline Age (day) & $32.6 \pm 1.4$ & $31.7 \pm 1.7$ & $32.0 \pm 1.5$ & $32.5 \pm 1.6$ \\
\hline Body weight (g) & $122.0 \pm 11.0$ & $121.1 \pm 10.8$ & $118.0 \pm 12.9$ & $116.7 \pm 8.3$ \\
\hline F2 pups & & & & \\
\hline Viability index $(\%)$ & & & & \\
\hline Day 0 & $98.89 \pm 2.63$ & $98.30 \pm 3.94$ & $99.30 \pm 2.13$ & $96.45 \pm 7.29$ \\
\hline Day 4 & $98.91 \pm 2.60$ & $97.85 \pm 3.25$ & $96.39 \pm 5.27$ & $97.89 \pm 3.38$ \\
\hline Day 21 & $99.34 \pm 2.87$ & $100.00 \pm 0.00$ & $100.00 \pm 0.00$ & $100.00 \pm 0.00$ \\
\hline Physical development & & & & \\
\hline Pinna unfolding (\%) & & & & \\
\hline No. of males examined & 19 & 22 & 19 & 17 \\
\hline Day 2 & $16.1 \pm 23.4$ & $9.3 \pm 20.5$ & $16.8 \pm 30.8$ & $25.7 \pm 36.5$ \\
\hline Day 3 & $91.3 \pm 24.7$ & $87.8 \pm 31.0$ & $75.4 \pm 42.5$ & $87.6 \pm 29.1$ \\
\hline Day 4 & $100.0 \pm 0.0$ & $100.0 \pm 0.0$ & $100.0 \pm 0.0$ & $100.0 \pm 0.0$ \\
\hline No. of females examined & 19 & 22 & 19 & 17 \\
\hline Day 2 & $29.8 \pm 29.2$ & $12.4 \pm 19.3$ & $19.8 \pm 31.3$ & $26.8 \pm 35.1$ \\
\hline Day 3 & $93.0 \pm 23.8$ & $86.1 \pm 32.4$ & $76.7 \pm 39.1$ & $88.0 \pm 28.9$ \\
\hline Day 4 & $100.0 \pm 0.0$ & $100.0 \pm 0.0$ & $99.5 \pm 2.3$ & $99.2 \pm 3.5$ \\
\hline
\end{tabular}


Reproductive toxicity study of dicyclohexyl phthalate.

Table 9. Continued

\begin{tabular}{|c|c|c|c|c|}
\hline DCHP (ppm) & 0 (Control) & 240 & 1200 & 6000 \\
\hline \multicolumn{5}{|l|}{ Incisor Eruption } \\
\hline No. of males examined & 19 & 22 & 19 & 17 \\
\hline Age (day) & $11.0 \pm 0.8$ & $10.7 \pm 0.8$ & $11.1 \pm 0.7$ & $10.7 \pm 0.9$ \\
\hline No. of females examined & 19 & 22 & 19 & 17 \\
\hline Age (day) & $11.0 \pm 0.9$ & $10.7 \pm 0.9$ & $11.3 \pm 0.8$ & $10.8 \pm 0.8$ \\
\hline \multicolumn{5}{|l|}{ Eye opening } \\
\hline No. of males examined & 19 & 22 & 19 & 17 \\
\hline Age (day) & $13.9 \pm 0.5$ & $13.9 \pm 0.6$ & $14.2 \pm 0.5$ & $14.0 \pm 0.6$ \\
\hline No. of females examined & 19 & 22 & 19 & 17 \\
\hline Age (day) & $13.8 \pm 0.6$ & $13.9 \pm 0.5$ & $14.0 \pm 0.6$ & $13.8 \pm 0.7$ \\
\hline $\begin{array}{l}\text { a: Mean } \pm \text { SD. } \\
\text { b: Viability on PND } 0 \text { (survival rate } \\
\text { c: Viability on PND } 4 \text { (the survival } \\
\text { d: Viability rate on PND } 21 \text { (weanir } \\
\text { e: Day of completion. } \\
\text { f: Body weight completion day. }\end{array}$ & $\begin{array}{l}\text { ivery })(\%)=(\mathrm{N} \\
\text { day } 4)(\%)= \\
(\%)=(\mathrm{Numb}\end{array}$ & $\begin{array}{l}\text { live pups on } \\
\text { f live pups o } \\
\text { oups on PND }\end{array}$ & $\begin{array}{l}\text { otal number o } \\
\text { / number of li } \\
\text { ber of live pul }\end{array}$ & $\begin{array}{l}\text { livered) } \times 100 \\
\text { n PND } 0) \times 100 \\
4) \times 100\end{array}$ \\
\hline
\end{tabular}

seminiferous tubules occurs in rats or mice treated with phthalate ester compounds (Gopinath et al., 1987a; Kandori et al., 2000), and in an earlier one-week oral repeated dose study of DCHP such focal atrophy was observed in 1 of 5 animals in the group treated with the dose of $2500 \mathrm{mg} / \mathrm{kg}$ (Lake et al., 1982). Thus, it is considered that the testicular change found in this study was indeed related to DCHP.

Reduction in the number of homogenizationresistant spermatids in the testes in F1 male parents of the 1200 and $6000 \mathrm{ppm}$ groups was observed. Since atrophy of the seminiferous tubules was observed in the $6000 \mathrm{ppm}$ group, it was considered that this was responsible for the change in the testicular spermatid head counts. In the $1200 \mathrm{ppm}$ group, reduction in the sperm counts was not accompanied by any obvious histological changes. Measurement of sperm count, however, is not considered necessary, because a reduction in sperm count can also be detected by histopathology alone, and with higher sensitivity (Mangelsdorf et al., 2003). In spite of the reduction in sperm counts, there were no effects recognized at any dose on sperm motility and copulation or fertility indices in this study. Sperm motility is known to be the most sensitive parameter, being found to have a high correlation with fertility (Mangelsdorf et al., 2003). Therefore, it is concluded that treatment with DCHP does not exert any adverse effects on reproductive functions.

With regard to the decrease of prostatic weight, no DCHP-related changes were observed in the weights of the male accessory reproductive organs in an earlier Hershberger assay, and thus, it was concluded that DCHP does not have androgenic or antiandrogenic activity (METI, 2002). General toxicological effects on body weights and food consumption were observed in the $6000 \mathrm{ppm}$ group, and whether these might have impacted the prostatic weights could not be elucidated.

Slight prolongation of the estrous cycle in F0 female parents of the $6000 \mathrm{ppm}$ group was also observed here, but this might have been a consequence of inhibition of body weight gain, as shown with restricted feeding (Chapin et al., 1993). As inhibition of body weight gain and food consumption were remarkable in the F0 parental female rats and stronger than in F1 females, we conclude that the prolongation of the estrous cycle was indeed a secondary change caused by inhibition of body weight gain. Taken together with the fact that neither estrogenic nor antiestrogenic activity was recognized in uterotrophic assays (METI, 2002), this change can not be considered a direct effect of DCHP treatment on the endocrine system.

Regarding the other histopathological findings, hepatocyte hypertrophy is often induced by administration of chemicals, as a kind of adaptive vital reaction as a consequence of induction of drug-metabolizing enzymes (Gopinath et al., 1987b; Greaves et al., 
1990a). It was earlier reported that hypertrophy of the hepatocyte and enhancement of the activities of several hepatic enzymes such as cytochrome P-450 were induced in a one week oral repeated dose study with DCHP in rats (Lake et al., 1982). Similarly hypertrophy or hyperplasia of thyroidal follicular epithelial cells may occur in relation to induction of hepatic drug-metabolizing enzymes, so that metabolism and degradation of thyroid hormones in the liver is acceler- ated (Gopinath et al., 1987c). Therefore, it is considered that the thyroidal change was linked to hypertrophy of hepatocytes.

Enhanced deposition of hyaline droplets in the renal proximal tubules was observed in F0 and F1 male parents given $6000 \mathrm{ppm}$, and this was accompanied by the appearance of the eosinophilic microbodies. It is well established that hyaline droplets in the proximal tubular epithelium appear when proteinous substances

Table 10. Organ weights for F1/F2 weanlings.

\begin{tabular}{|c|c|c|c|c|}
\hline DCHP (ppm) & 0 (Control) & 240 & 1200 & 6000 \\
\hline \multicolumn{5}{|l|}{ F1 offspring } \\
\hline No. of male F1 weanlings examined & 20 & 22 & 20 & 22 \\
\hline Final body weight $(\mathrm{g})$ & $62.49 \pm 4.64^{\mathrm{a}}$ & $62.44 \pm 5.43$ & $61.71 \pm 4.65$ & $55.20 \pm 3.65^{* *}$ \\
\hline \multirow[t]{2}{*}{ Brain $(\mathrm{g})$} & $1.517 \pm 0.054^{b}$ & $1.521 \pm 0.055$ & $1.530 \pm 0.042$ & $1.497 \pm 0.040$ \\
\hline & $2.438 \pm 0.165^{\mathrm{c}}$ & $2.452 \pm 0.207$ & $2.492 \pm 0.176$ & $2.721 \pm 0.172 * *$ \\
\hline \multirow[t]{2}{*}{ Thymus (mg) } & $270.10 \pm 39.28$ & $262.25 \pm 37.58$ & $261.49 \pm 34.82$ & $233.07 \pm 28.86^{* *}$ \\
\hline & $431.51 \pm 47.84$ & $420.47 \pm 51.56$ & $424.50 \pm 53.53$ & $422.45 \pm 46.58$ \\
\hline \multirow[t]{2}{*}{ Spleen $(\mathrm{g})$} & $0.299 \pm 0.053$ & $0.325 \pm 0.056$ & $0.321 \pm 0.062$ & $0.249 \pm 0.039 * *$ \\
\hline & $0.477 \pm 0.068$ & $0.519 \pm 0.069$ & $0.518 \pm 0.078$ & $0.451 \pm 0.060$ \\
\hline No. of female F1 weanlings examined & 20 & 23 & 20 & 22 \\
\hline Final body weight (g) & $58.86 \pm 3.93$ & $59.55 \pm 5.39$ & $59.78 \pm 5.17$ & $52.27 \pm 3.07 * *$ \\
\hline \multirow[t]{2}{*}{ Brain $(\mathrm{g})$} & $1.486 \pm 0.040$ & $1.468 \pm 0.041$ & $1.477 \pm 0.051$ & $1.449 \pm 0.025^{* *}$ \\
\hline & $2.535 \pm 0.177$ & $2.483 \pm 0.213$ & $2.486 \pm 0.196$ & $2.780 \pm 0.152 * *$ \\
\hline \multirow[t]{2}{*}{ Thymus (mg) } & $265.10 \pm 44.49$ & $266.00 \pm 38.25$ & $270.11 \pm 39.65$ & $239.18 \pm 36.12$ \\
\hline & $449.42 \pm 62.19$ & $448.58 \pm 66.24$ & $451.39 \pm 49.11$ & $456.53 \pm 53.44$ \\
\hline \multirow[t]{2}{*}{ Spleen $(\mathrm{g})$} & $0.286 \pm 0.056$ & $0.308 \pm 0.063$ & $0.298 \pm 0.044$ & $0.247 \pm 0.033 * *$ \\
\hline & $0.485 \pm 0.078$ & $0.517 \pm 0.089$ & $0.499 \pm 0.060$ & $0.472 \pm 0.056$ \\
\hline \multicolumn{5}{|l|}{ F2 offspring } \\
\hline No. of male F1 weanlings examined & 19 & 22 & 19 & 17 \\
\hline Final body weight (g) & $66.36 \pm 3.86$ & $62.75 \pm 5.30$ & $62.79 \pm 6.23$ & $59.93 \pm 6.48 * *$ \\
\hline \multirow[t]{2}{*}{ Brain $(g)$} & $1.515 \pm 0.048$ & $1.506 \pm 0.059$ & $1.500 \pm 0.060$ & $1.525 \pm 0.081$ \\
\hline & $2.289 \pm 0.121$ & $2.411 \pm 0.151$ & $2.407 \pm 0.222$ & $2.567 \pm 0.255^{* *}$ \\
\hline \multirow[t]{2}{*}{ Thymus (mg) } & $285.17 \pm 53.26$ & $251.79 \pm 34.70$ & $263.69 \pm 46.91$ & $248.24 \pm 50.07$ \\
\hline & $428.79 \pm 70.03$ & $401.42 \pm 45.16$ & $418.70 \pm 53.77$ & $412.00 \pm 51.37$ \\
\hline \multirow[t]{2}{*}{ Spleen $(\mathrm{g})$} & $0.357 \pm 0.066$ & $0.337 \pm 0.051$ & $0.316 \pm 0.055$ & $0.295 \pm 0.066^{* *}$ \\
\hline & $0.537 \pm 0.091$ & $0.537 \pm 0.074$ & $0.501 \pm 0.059$ & $0.491 \pm 0.081$ \\
\hline \multirow{2}{*}{$\begin{array}{l}\text { No. of female F1 weanlings examined } \\
\text { Final body weight }(\mathrm{g})\end{array}$} & 19 & 22 & 19 & 16 \\
\hline & $60.59 \pm 4.94$ & $59.70 \pm 4.16$ & $59.11 \pm 4.67$ & $56.38 \pm 4.66^{*}$ \\
\hline Brain (g) & $1.454 \pm \quad 0.070$ & $1.449 \pm 0.062$ & $1.459 \pm 0.062$ & $1.465 \pm 0.058$ \\
\hline & $2.408 \pm 0.133$ & $2.435 \pm 0.136$ & $2.481 \pm 0.201$ & $2.626 \pm 0.191 * *$ \\
\hline Thymus (mg) & $270.81 \pm 41.17$ & $257.86 \pm 36.53$ & $267.59 \pm 51.30$ & $237.79 \pm 43.97$ \\
\hline & $446.96 \pm 60.01$ & $432.05 \pm 52.78$ & $451.49 \pm 69.38$ & $422.93 \pm 56.57$ \\
\hline Spleen $(\mathrm{g})$ & $0.314 \pm 0.061$ & $0.324 \pm 0.062$ & $0.313 \pm 0.066$ & $0.281 \pm 0.043$ \\
\hline & $0.517 \pm 0.084$ & $0.544 \pm 0.095$ & $0.527 \pm 0.087$ & $0.502 \pm 0.072$ \\
\hline
\end{tabular}

\footnotetext{
a: Mean \pm SD.

b: Absolute organ weight.

c: Relative organ weight.

*: Significantly different from the control value, *, $\mathrm{p}<0.05 ; * *, \mathrm{p}<0.01$.
} 
Reproductive toxicity study of dicyclohexyl phthalate.

are reabsorbed, especially in male rats, and that the amount of hyaline droplets derived from $\alpha 2 \mathrm{U}$ globulin increases with aging (Greaves et al., 1990b). Moreover, it is also known that eosinophilic microbodies often appear simultaneously with increased hyaline droplets, and that the structure of eosinophilic microbodies includes $\alpha 2 \mathrm{U}$ globulin (Watanabe and Nishikawa, 2000). Taking the available evidence into account, the renal changes were concluded to be related to increased deposition of $\alpha 2 \mathrm{U}$ globulin, as a rat specific effect caused by DCHP.

In conclusion, from the present study of DCHP administered to rats over two generations, the no observed effect level (NOEL) for effects on the parental animals including those on the endocrine system was estimated to be $240 \mathrm{ppm}$. With regard to the reproductive toxicological effects on the parental animals the NOEL was judged to be $240 \mathrm{ppm}$ in males and $1200 \mathrm{ppm}$ in females, and with regard to effects on the offspring, the NOEL was judged to be $240 \mathrm{ppm}$ in males and $1200 \mathrm{ppm}$ in females.

\section{ACNOWLEDGMENT}

The present study was supported by the Ministry of Economy, Trade and Industry, Japan. The authors are grateful to the members of Mitsubishi Chemical Safety Institute who have been involved in this study.

\section{REFERENCES}

Bartlett, M.S. (1937): Properties of sufficiency and statistical tests. Proc. Roy. Soc., A160, 268-282.

Chapin, R.E., Gulati, D.K., Barnes, L.H. and Teague, J.L. (1993): The effects of feed restriction on reproductive function in Sprague-Dawley rats. Fundam. Appl. Toxicol., 20, 23-29.

Dunnett, C. W. (1955): A multiple comparison procedure for comparing several treatments with a control. J. Am Stat. Assoc., 50, 1096-1121.

Dunnett, C. W. (1964): New tables for multiple comparison with a control. Biometrics, 20, 482-492.

Fisher, J.S. (2004): Environmental anti-androgens and male reproductive health: Focus on phthalates and testicular dysgenesis syndrome. Reproduction, 127, 305-315.

Fisher, R. A. (1955): Statistical methods and scientific induction. J.R. Stat. Soc. [B], 17, 69-78.

Gopinath, C., Prentice, D.E. and Lewis, D.J. (1987a): The reproductive system. Male reproductive system. Testis and epididymis. In: Gopinath C,
Prentice DE, Lewis DJ, editors. Atlas of Experimental Toxicological Pathology. Lancaster: MTP Press Limited; pp.97-100, Lancaster.

Gopinath, C., Prentice, D.E. and Lewis, D.J. (1987b): The liver. Morphological lesions in the liver. Hypertrophy. In: Gopinath C, Prentice, DE, Lewis DJ, editors. Atlas of Experimental Toxicological Pathology. Lancaster: MTP Press Limited; p.53, Lancaster.

Gopinath, C., Prentice, D.E. and Lewis, D.J. (1987c): The endocrine glands. Thyroid. In: Gopinath C, Prentice DE, Lewis DJ, editors. Atlas of Experimental Toxicological Pathology. Lancaster: MTP Press Limited; pp.112-113, Lancaster.

Gray, L.E., Ostby, J., Furr, J., Wolf, C.J., Lambright, C., Parks, L., Veeramachaneni, D.N., Wilson, V., Price, M., Hotchkiss, A., Orlando, E. and Guillette, L. (2001): Effects of environmental antiandorogens on reproductive development in experimental animals. Human Reproduction Update, 7, 248-264.

Greaves, P. Digestive system 2. (1990a): Liver. Hepatocellular hypertrophy and hyperplasia. In (Greaves, P., ed.), Histopathology of Preclinical Toxicity Studies. Amsterdam: Elsevier; pp.403406, New York.

Greaves, P. Urinary tract. Kidney. Hyaline droplets. (1990b): (Greaves, P., ed.), Histopathology of Preclinical Toxicity Studies. Amsterdam: Elsevier; pp.532-538, New York.

HSDB (2001): Hazardous Substance Data Bank. National Library of Medicine.

Kandori, H., Cyatani, F. and Miyajima, H. (2000), Yusei-seisyokuki. Hisyuyousei-byouhen. Seiso (Male reproductive organs. Non-neoplastic lesions. Testis.) Maekawa A, responsible editor. Toxicity Histopathology: The Japanese Society of Toxicologic Pathology; pp.287-291, Nagoya (in Japanese).

Kruskal, W.H. and Wallis, W.A. (1952): Use of ranks in one-criterion variance analysis. J. Am. Statist. Assoc., 47, 583-621.

Lake, B.G., Foster, J.R., Collins, M.A., Stubberfield, C.R., Gangolli, S.D. and Srivastava, S.P. (1982): Studies on the effects of orally administered dicyclohexyl phthalate in the rat. Acta Pharmacol Toxicol (Copenh)., 51, 217-226.

Mangelsdorf, I., Buschmann, J. and Orthen, B. (2003): Some aspects relating to the evaluation of the effects of chemicals on male fertility. Regul Toxicol Pharmacol, 37, 356-369. 
METI (2002): Current Status of Testing Methods Development for Endocrine Disrupters. Ministry of Economy, Trade and Industry, Japan.

OECD (1983): Guidelines for testing of chemicals, Section 4-Health Effects, Guideline No.416. Organization for Economic Co-Operation and Development, May 26, 1983.

Shultz, V.D., Phillips, S., Sar, M., Foter, P.M. and Gaido, K.W. (2001): Altered gene profiles in fetal rat testes after in utero exposure to di(nbutyl) phthalate. Toxicol. Sci., 64, 233-242.

Watanabe, M. and Nishikawa, A. (2000): Hisyuyousei-byouhen (Kidneys.Non-neoplastic lesions). Maekawa A, responsible editor. Toxicity histopathology. The Japanese Society of Toxicologic Pathology; pp.250-254, Nagoya (in Japanese). 